\title{
Sebrae:
}

\section{O jovem empreendedor}

JOSÉ LUIZRICCA

C

om o fIM do ciclo da Revolução Industrial, o mundo do trabalho vem passando por transformações que, no seu conjunto, configuram o ingres-

so em uma nova etapa do processo de produção de bens e serviços e das relações de trabalho.

$\mathrm{N}$ a economia, a globalização trouxe consigo a batalha pela conquista dos mercados. C onseguem vencer esta batal ha os países que oferecem produtos de melhor qualidade a preços mais competitivos. Para tanto, as organizações vêm passando por processos de ajustes estruturais e fusões, permanecendo nos empregos, em geral, os mais qualificados.

$\mathrm{N}$ a tecnologia, os avanços das últimas décadas vêm substituindo não só o esforço físico como também boa parte da atividade intelectual, possibilitando às organizações aumentar a produtividade sem que isso se traduza em maior número de postos de trabalho, desvinculando assim a produção do emprego. E o que acontece com os empregos? U ma das conseqüências da "era do conhecimento" no Brasil é o crescimento exponencial da informalidade no mundo do trabalho.

N o Brasil, hoje, mais de $50 \%$ da População E conomicamente Ativa (PEA) está trabal hando sem carteira assinada. Como fica a auto-estima e a dignidade de quem não possui a proteção social proporcionada pelo emprego formal, sobretudo no que diz respeito à população mais jovem? Seria o fim do emprego? Evidente que não, uma vez que está em processo uma mudança de paradigma.

M uitas vezes procuro imaginar como seria viver em 1804 e tentar vislumbrar o que estaria acontecendo em 1850 ou 1870. I mpossível precisar o que estaria acontecendo cinqüenta, setenta anos à frente, em 1803. N o entanto, naquele período, o mundo mudou. Algo novo surgiu: a empresa, e com ela o ciclo industrial e a R evolução Industrial. H oje, duzentos anos depois, queiramos ou não, este ciclo chegou ao fim.

I sso não significa dizer, no entanto, que a oferta de empregos tenha chegado ao fim, mas apenas houve uma mudança - em termos de estilo e de oferta engendrada não só pela própria dinâmica das novas tecnologias, mas também pelo seu impacto na sociedade e na própria natureza do trabalho. H oje não é preciso mais se trabalhar dentro de uma indústria ou em um ambiente físico limitado. Com a tecnologia disponível é possível desempenhar alguma atividade em qualquer lugar que esteja ligado a um sistema de rede, com acesso a toda informação necessária. 
M asisso é novo demais. É necessário perceber esta nova realidade, conhecêla e inserir-se em sua dinâmica. A vida mudou. E a sociedade exige que tenhamos cada vez mais visão para saber o que vai acontecer daqui para a frente.

A pesquisa GEM (Global E ntrepreneurship M onitor) ${ }^{1}$, que mede a taxa de empreendedorismo em vários países, e real izada anualmente sob coordenação de universidades dos E stados U nidos e da I nglaterra, mostra que o Brasil, hoje, é o sexto país mais empreendedor do mundo. A GEM monitora, ao todo, 31 países do mundo, que, juntos, respondem por mais de $90 \%$ do PIB mundial.

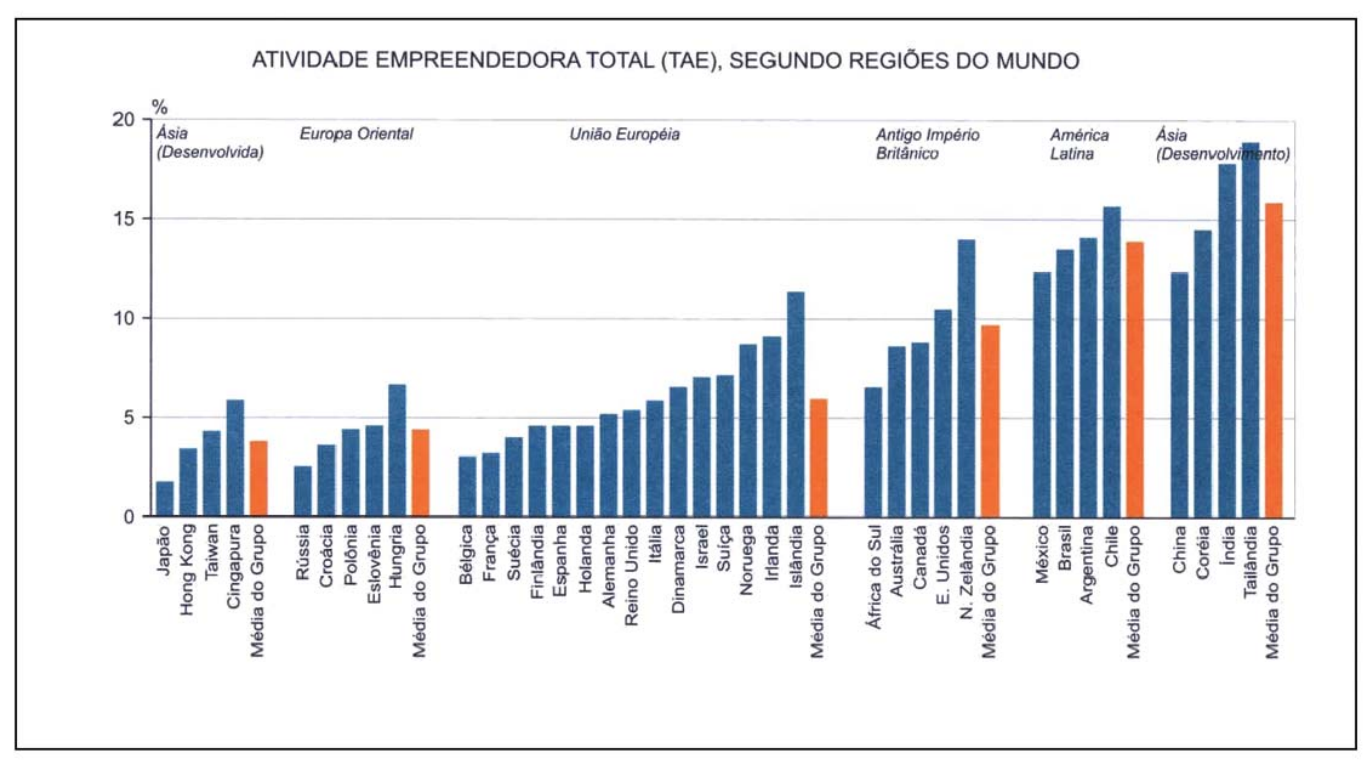

$\mathrm{N}$ as pesquisas recentes, foram revistos os critérios para identificar naturezas distintas de empreendedorismo nos diferentes países, a saber, empreendedorismo por necessidade e por oportunidade.

Q uando se fala em empreendedorismo por oportunidade, o Brasil cai para a décima posição. Quando se trata de empreendedorismo por necessidade, no entanto, ocupamos a quinta posição. A título de comparação, a França é o primeiro país do mundo em empreendedorismo por oportunidade e praticamente não possui empreendedores por necessidade.

I sso significa que grande parte do empreendedorismo desenvolovido no Brasil resulta de uma questão de sobrevivência, uma vez que não há trabalho para todos e há necessidade de geração de renda. I sso reflete uma outra questão muito complicada. N o Estado de São Paulo, 99\% das empresas instaladas são classificadas como micro e pequenas. N esta última categoria, contam-se 1,3 miIhão de empresas, as quais respondem por mais de $60 \%$ dos postos de trabalho da iniciativa privada no Estado. 0 aspecto perverso destes dados é que apenas $40 \%$ das M PE recém-abertas permanecem no mercado após cinco anos de vida². 


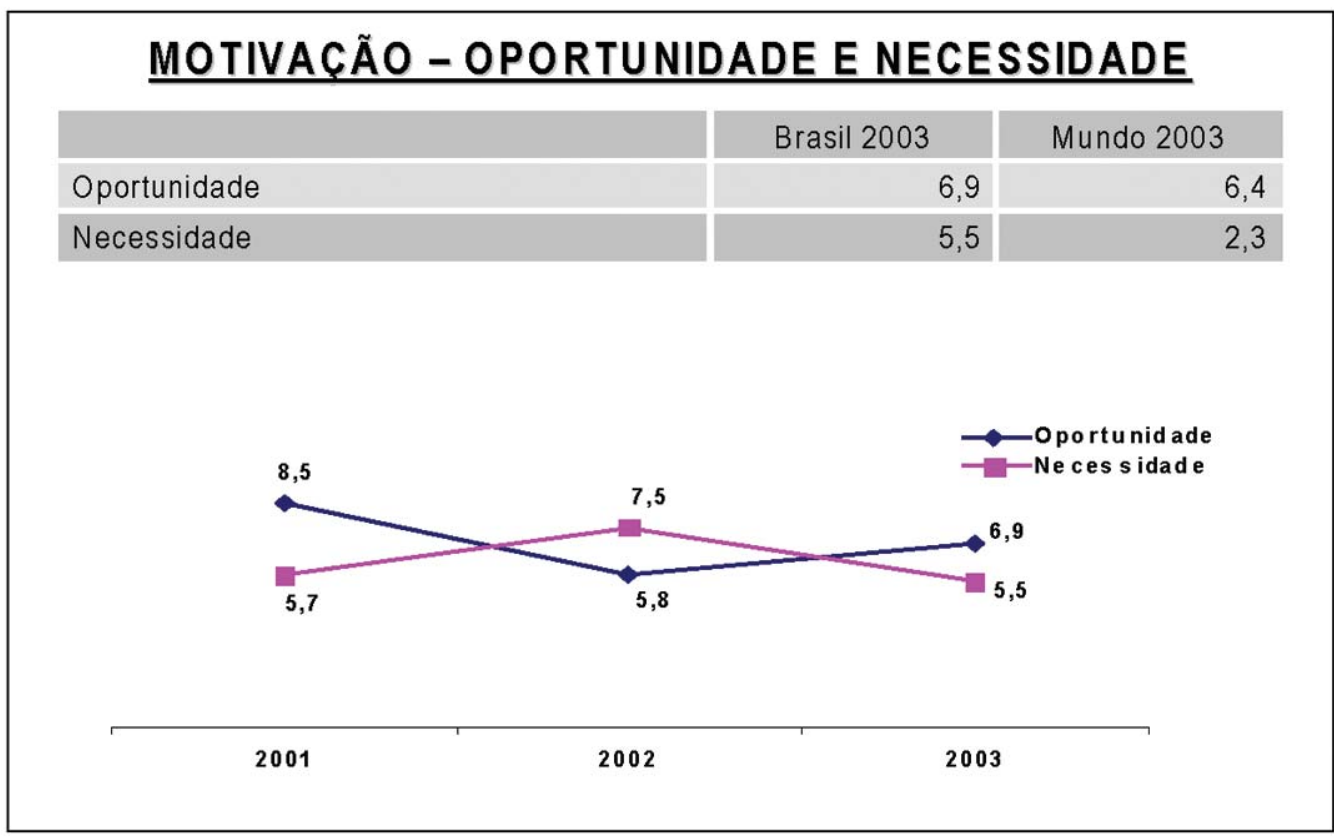

Fonte: Pesquisa GEM , 2003. Base: \% população adulta.

Taxa de mortalidade das empresas (rastreamento nov./ dez., 2002)

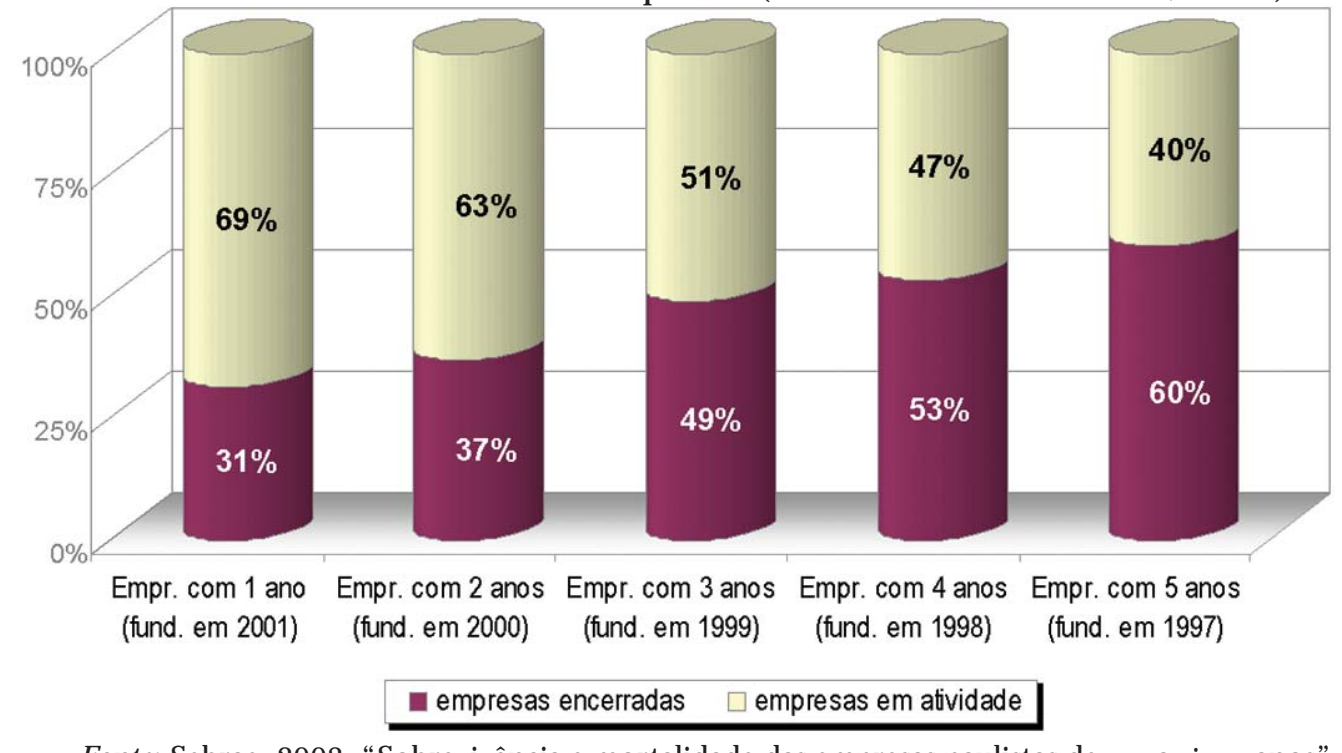

Fonte: Sebrae, 2003, "Sobrevivência e mortalidade das empresas paulistas de um a cinco anos".

Trata-se de uma situação extremamente grave e com conseqüências desastrosas, não só em termos de perspectiva de vida como no de auto-estima. N ão encontrando trabalho e incapaz de gerar renda, esta população permanece em total desalento e sem motivação para novas iniciativas. Em vista disso, transformar o empreendedorismo por necessidade de sobrevivência em oportunidades de negócios é o grande desafio que se coloca para os governos e as instituições como o Sebrae, cuja missão é " promover a competitividade e o desenvolvimento sustentável das micro e pequenas empresas". 
Sendo responsáveis por mais de $60 \%$ das pessoas ocupadas nas atividades privadas, as M PEs se constituem num celeiro de empregos. Pesquisas de Conjuntura ${ }^{3}$ realizadas pelo Sebrae-SP sobre as M PEs mostram que, nos primeiros cinco meses de 2004, enquanto seu faturamento médio caiu em até $11 \%$, quando comparado ao mesmo período do ano passado, o nível de pessoal ocupado sofreu queda de apenas $0,4 \%$ I sso reforça a idéia de que as pequenas empresas constituem um segmento da economia que atua como um "colchão" contra o desemprego porque, como são pequenas e empregam pouca gente, não fazem ajustes no pessoal em momentos de crise, como acontece na grande empresa. Além de empregadoras, elas asseguram maior estabilidade quando comparadas às grandes empresas.

Faturamento R eal e Pessoal O cupado nas M PEs do Estado de São Paulo (jan./ 03=100)

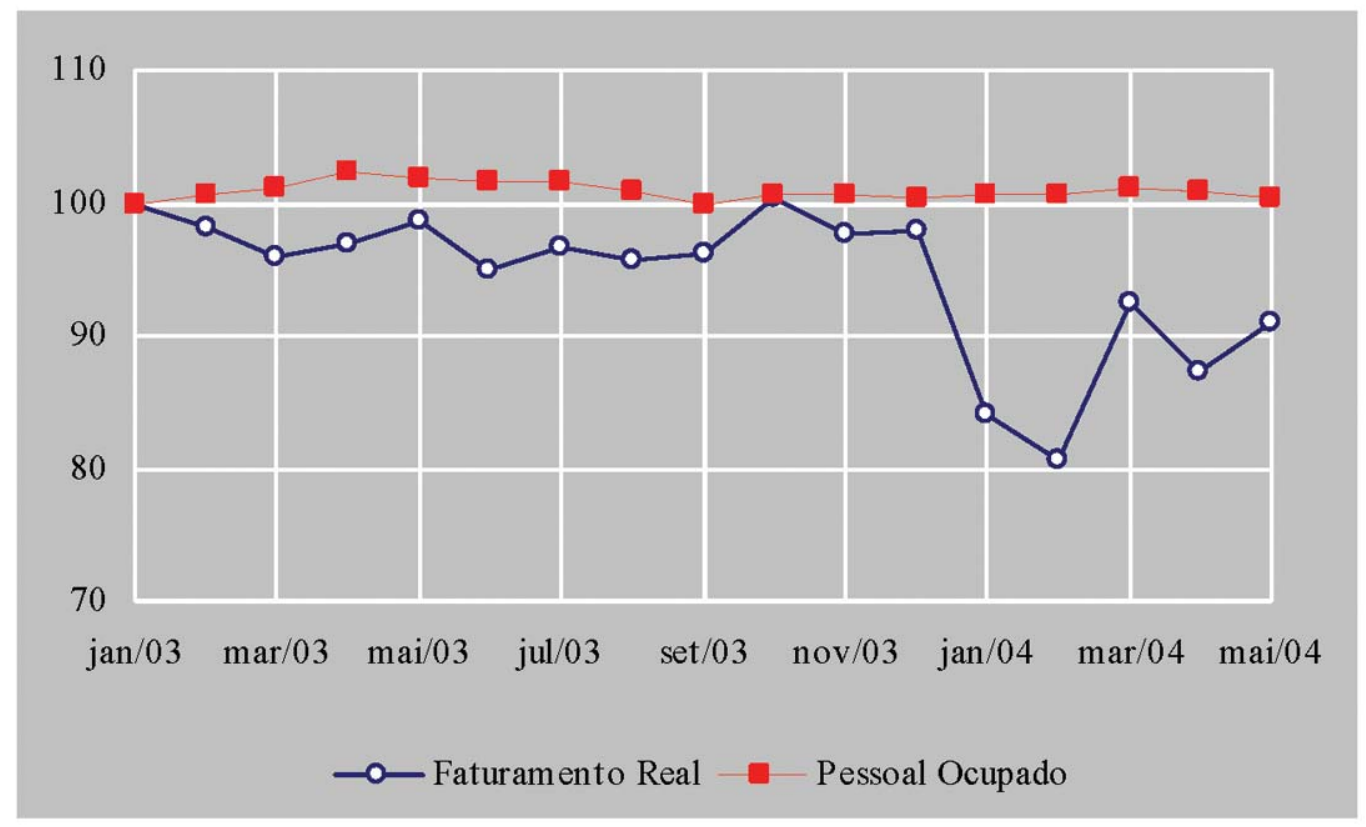

Fonte: Sebrae-SP, 2004, Indicadores Sebrae-SP: pesquisa de conjuntura.

O Sebrae atua nesse quadro com o objetivo de tranforformar as M PE s e o empreendedorismo numa oportunidade digna de trabalho. Precisamos encarar esse turbilhão que estamos vivendo como traumas da mudança. $\mathrm{N}$ ão podemos concordar - e eu particularmente nunca concordei - com a teoria de que devemos precarizar o mercado de trabal ho e flexibilizar os direitos do trabalhador. 0 que se deve fazer, na realidade, é voltar a atenção para o futuro. 0 modelo do desenvolvimento industrial não vai se repetir e o "novo trabalho" será diferente daquele vivenciado na era industrial, com novos conceitos e melhor perspectiva de qualidade de vida. 
Estamos criando um novo modelo, assim como o que foi criado no século XIX. E uma de suas bases é justamente o empreendedorismo, o trabalho por conta própria, a capacidade de gerar o próprio negócio, os próprios recursos e contribuir para a sociedade de forma mais pessoal.

0 desenvolvimento do comportamento empreendedor passa, necessariamente, pela valorização e pela capacitação para o associativismo. A associação, a rede social, o terceiro setor, a vida da forma como se vê hoje e tendo como perspectiva a preocupação com a sobrevivência no planeta, com a ecologia, a indignação com a miséria; toda essa dinâmica está gerando novas oportunidades de trabal ho e de renda que serão, inclusive, vetores de oportunidades para o trabaIho no futuro.

Acoplando toda essa questão a uma visão de longo prazo e iniciando a construção do futuro a partir de agora, temos de considerar o empreendedorismo como uma oportunidade a mais.

\section{E mprego ou trabalho para o jovem?}

O jovem, hoje, é o segmento mais displicentemente olhado pela sociedade,uma vez que não existe política pública efetiva capaz de engajá-lo na sociedade.

Ainda que o esperado crescimento econômico possa ajudar a reduzir os índices de desemprego no País, é difícil acreditar que algum dia voltaremos a ter algo parecido com o pleno emprego. E se voltarmos, seguramente não será com base no modelo das grandes corporações.

O ra, se o emprego da forma que conhecemos hoje tende a ser cada vez mais escasso, por que continuamos exclusivamente a formar jovens para serem empregados? Por que não formamos também nossos jovens para serem empregadores? $\mathrm{O}$ u, melhor, empreendedores?

A maioria de nós foi criada para ser bons funcionários de uma grande organização. Dificilmente passaria na cabeça de quem sempre pensou em ter um excelente e estável cargo numa empresa a idéia de abrir um incerto pequeno negócio. Acontece que esse mundo mudou profundamente e não podemos impor aos jovens nossos desejos, anseios e medos. Se fizermos isso estaremos condenando-os à infelicidade e, boa parte deles, talvez a maioria, ao desemprego.

Precisamos também formar nossos jovens para o empreendedorismo. Para o trabalho autônomo, para o associativismo, para o cooperativismo, que surgem como novas possibilidades de geração de trabalho e renda. E ssas palavras apavoram a maioria das pessoas com mais de quarenta anos, mas o novo mundo se constrói olhando para frente e não lutando para tentar segurar um passado que definha.

I sso não significa que apenas o empreendedorismo vai resolver toda a demanda por trabalho e renda. É evidente que a relação de emprego continuará a existir. Entretanto, ela não será mais exclusiva nem tampouco a grande geradora de postos de trabalho. $\mathrm{H}$ oje, menos da metade dos empregados possuem rela- 
ções formais de trabalho. E sse número fica cada vez mais reduzido. É mais uma vez a realidade indicando o caminho.

É preciso que a idéia das novas formas de trabalho, e não exclusivamente de emprego, seja levada para o jovem desde o ciclo básico até a U niversidade, de modo que ele seja educado para a mudança e não para estabilidade. Ele deve ser ensinado a conviver com o risco e aprender com ele, a pensar grande, a ter autoestima, coragem, confiança e capacidade para gerir sua própria vida, vendo na mudança a o portunidade e não a ameaça. Abrir um pequeno negócio deveria ser objeto de realização pessoal de não de falta de opção.

Com base nisso tudo, o Sebrae se engaja em alguns projetos fundamentais para o jovem. U m deles é o programa U niversitário Cidadão, que capacita jovens para que desenvolvam projetos sociais. O s universitários são formados numa série de programas voltados para o terceiro setor, para que eles não só prestem serviços como estagiários, mas para que também possam verificar outras possibilidades de ocupação nem sempre visíveis nesse mercado que tem a empresa como única e exclusiva fonte de trabalho.

U m outro projeto tem como foco a formação do jovem do nível médio, para que ele desenvolva conceitos de empreendedorismo e tenha a oportunidade de vir a tornar um empreendedor. A ação inclui um programa suplementar de treinamento para que o jovem se associe e, por meio da associação, possa desenvolver o seu próprio negócio.

Por ser muito ousado, o terceiro projeto foi extremamente discutido, porque pretende levar o empreendedorismo para crianças do nível fundamental de ensino. Para este segmento, o Sebrae desenvolveu um curso chamado Jovens E mpreendedores - Primeiros Passos. Os professores são capacitados por facilitadores do Sebrae e o curso pode ser incluído no currículo regular das próprias escolas onde esses professores trabalham. São J osé dos C ampos foi o município escolhido para fazer um programa-piloto, onde foram treinadas treze turmas de professores e trinta mil alunos passaram pelo processo. Ao término de cada ciclo de aprendizagem, o município faz uma feira de empreendedorismo para que o jovem possa mostrar o que aprendeu e os projetos que desenvolveu. Esse programa já pode, inclusive, ser disponibilizado aos municípios do Estado de São Paulo que se interessarem em implementá-lo.

Para terminar, repito que precisamos olhar o empreendedorismo de uma maneira um pouco menos mistificada e mais popularizada; ele deve entrar e fazer parte do currículo das escolas. Ao desenvolver atitudes empreendedoras, estamos ampliando as possibilidades de escolha para a realização pessoal e profissional.

Complementando os projetos de capacitação, devemos incentivar também programas de incubadoras de empresas, de associações de jovens, de empresas juniores, programas de responsabilidade social das empresas, buscando fazer com que as empresas adotem os jovens não apenas no primeiro emprego, mas também na orientação do empreendedorismo. 
Precisamos ainda de redes sociais mais efetivas, para que possamos empreender nos novos ramos de atividade, tais como o turismo, a cultura, e toda a área social, que é um mundo de novas oportunidades. Além de nos aventurar para empreender tanto na condição de empregados como na de empregadores, procedendo assim a uma enorme mudança cultural.

N otas

1 A Pesquisa completa pode ser obtida nos sites http:/ / www.gemconsortium.org/ (http:/ / www.gemconsortium.org/ category_list.asp?cid=123) (http:/ / www.ibqppr.org.br/ index.php?menu=prodE mpreende)

2 A Pesquisa de M ortalidade completa pode ser obtida no site do Sebrae-SP (www. sebraesp.com.br)

3 A Pesquisa de Conjuntura completa pode ser obtida no site do Sebrae-SP (www. sebraesp.com.br)

J osé L uiz R icca é engenheiro industrial, formado pela U niversidade Federal Fluminense com especialização em G estão H umana, D esenvolvimento E mpresarial e Balanço Social. Foi secretário das R elações de Trabalho do M inistério do Trabalho, secretário E stadual do E mprego e Relações do Trabalho (SERT) e hoje é diretor superintendente do SebraeSP.

Texto recebido e aceito para publicação em 20 de julho de 2004. 